http://nv.nltu.edu.ua

https://doi.org/10.15421/40280230

$@$ Correspondence author

Article received 27.03.2018 p.

I. M. Zhuravel

Article accepted 29.03.2018 p.

izhuravel@ukr.net

удК 004.932.2:620.18

I. М. Журавель

Національний університет "Львівська політехніка", м. Львів, Україна

\title{
ВИБІР НАЛАШТУВАНЬ ПІД ЧАС ОБЧИСЛЕННЯ ПОЛЯ ФРАКТАЛЬНИХ РОЗМІРНОСТЕЙ ЗОБРАЖЕННЯ
}

\begin{abstract}
Результати досліджень в біології, медицині, дистанційному зондуванні Землі, матеріалознавстві доволі часто представляють у вигляді цифрових зображень. Такі зображення, здебільшого, характеризуються не дуже високою візуальною якістю та складною структурою. Усі ці чинники істотно впливають на подальший аналіз візуальних даних. Незважаючи на інтелектуальні властивості зорового сприйняття, людина не може справитися з великим потоком інформації та забезпечити необхідну продуктивність іiї опрацювання, тому кількісний аналіз візуальних даних доцільно перекласти на обчислювальні системи. Це призвело до того, що останнім часом розвиток значного сегменту сучасних інформаційних технологій націлений на створення методів опрацювання та аналізу візуальної інформації. Результат процесу опрацювання та аналізу є надзвичайно важливим, оскільки він лежить в основі прийняття відповідальних рішень, для прикладу, в медицині чи на виробництві. Традиційні підходи, які базуються на евклідовій геометрії, не завжди є ефективними в разі опрацювання зображень зі складною структурою. Перспективним інструментарієм для аналізу таких зображень $є$ фрактальна розмірність. Загалом вона дає змогу обчислювати тільки глобальні характеристики зображення. Для кількісного аналізу складноструктурованих зображень доцільно формувати поле фрактальних розмірностей. Встановлено, що для обчислення поля фрактальних розмірностей важливим $є$ правильний вибір налаштувань. Серед них треба виділити - розмір локальної апертури, крок зміщення та метод бінаризації. Розмір локальної апертури істотно впливає на деталізацію під час аналізу зображення. Для найкращої локалізації розмір ковзного околу повинен бути співмірним з розміром об'єктів зацікавлення на зображенні. Другим важливим параметром $є$ крок зміщення локальної апертури. Він пропорційний до часу опрацювання та обернено пропорційний до розміру зображення поля фрактальних розмірностей. Збільшення кроку зміщення доцільне під час опрацювання зображень великих розмірів, але це призводить до зменшення деталізації об'єктів. Оскільки більшість методів обчислення фрактальних розмірностей використовує за вхідні бінарні зображення, важливим $є$ вибір методу порогової бінаризації, який має забезпечити найкращу деталізацію об'єктів інтересу.
\end{abstract}

Ключові слова: аналіз цифрових візуальних даних; методи порогової бінаризації; локальна апертура; крок зміщення; деталізація об'єктів.

Вступ. Доволі часто інформація, яка отримується у різноманітних комплексах технічних засобів при проведенні неруйнівного контролю, представляється у вигляді зображень. Візуальний підхід до аналізу таких даних здебільшого не дає вичерпних та достовірних результатів. Особливо це $є$ актуальним для зображень, які містять велику кількість дрібних об'єктів, мають складну структуру, вимагають кількісних оцінок геометричних даних тощо. Традиційні засоби оброблення зображень $\epsilon$ малоефективними та дають змогу отримати тільки загальні відомості про досліджуване зображення. Вирішення спеціалізованих задач потребує розроблення та застосування нових підходів та інструментів. Дослідження у цьому напрямку показали широкі можливості фрактальних розмірностей для аналізу зображень зі складною структурою (Zhuravel', Svirs'ka, 2015; Zhuravel, \& Vorobel, 2007). Під час аналізу складноструктурованих об'єктів, окрім фрактальних розмірностей, використовують таке поняття, як поле фрактальних розмірностей. Застосування цієї технології потребує глибо- ких знань та вмінь дослідника як у сфері оброблення зображень, так і в теорії фракталів для правильного вибору параметрів налаштувань методів обчислення та побудови поля фрактальних розмірностей.

Вилив розмірів локальної апертури на результати формування поля фрактальних розмірностей зображення. Під час побудови поля фрактальних розмірностей деякого зображення $M \times N$ його сканують локальною апертурою, здебільшого квадратної форми, з розмірами $n \times n$. Центральний елемент апертури збігається 3 поточним елементом зображення $(i, j)$. Фрактальна розмірність цього локального околу $n \times n$ присвоюється елементу $D(i, j)$ поля фрактальних розмірностей з координатами $(i, j)$. Просканувавши в такий спосіб усе зображення, отримують поле фрактальних розмірностей $D$ (Zhuravel \& Vorobel, 2007).

Ще одним важливим параметром $\epsilon$ крок зміщення $k$ локальної апертури відносно свого попереднього розміщення. За $k=1$ апертура $\epsilon$ ковзною, за $k>1$ - "стрибкоподібною" по полю зображення. У випадку, коли $k=1$,

Інформація про авторів:

Журавель Ігор Михайлович, канд. техн. наук, ст. науковий співробітник, доцент кафедри безпеки інформаційних технологій. Email: izhuravel@ukr.net

Цитування за ДСту: Журавель І. М. Вибір налаштувань під час обчислення поля фрактальних розмірностей зображення. Науковий вісник НлТУ України. 2018, т. 28, № 2. С. 159-164.

Citation APA: Zhuravel, I. M. (2018). The Choice of Parameters when Calculating the Fractal Dimension of the Image. Scientific Bulletin of UNFU, 28(2), 159-164. https://doi.org/10.15421/40280230 
розмір сформованого поля фрактальних розмірностей $D$ співпадатиме з розміром вихідного зображення, а за $k>1$ - буде меншим.

Дослідимо вплив розмірів локальної апертури $n \times n$ та кроку зміщення $k$ на результат формування поля фрактальних розмірностей $D$. За вхідне приймемо деяке фрактографічне зображення сталі 12Х1МФ (рис. 1).

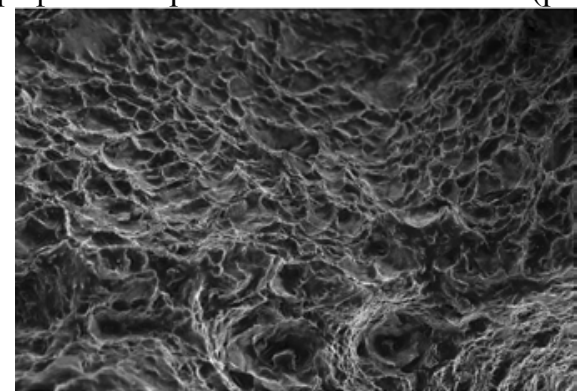

Рис. 1. Фрактографічне зображення сталі $12 \mathrm{X} 1 \mathrm{MФ}$

На основі вхідного зображення (див. рис. 1) сформуємо поле фрактальних розмірностей, використавши локальні апертури 3 розмірами $3 \times 3,7 \times 7,15 \times 15$ та $31 \times 31$ піксель. При цьому крок зміщення $k$ приймемо

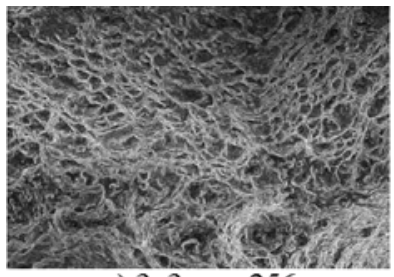

a) $3 \times 3, q=256$

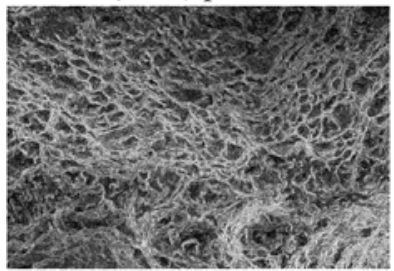

д) $3 \times 3, q=64$

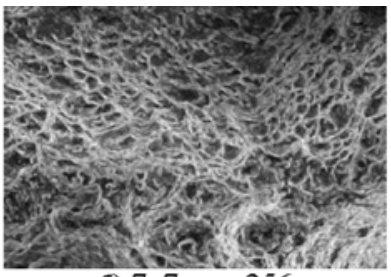

б) $7 \times 7, q=256$

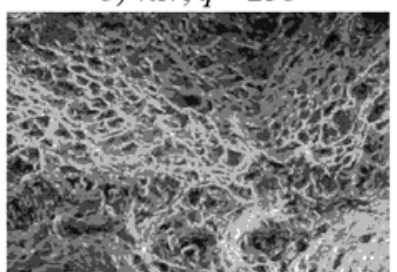

e) $7 \times 7, q=16$

таким, що дорівнює одиниці, тобто локальна апертура буде ковзною.

Вибір методу обчислення фрактальної розмірності не має принципового значення. У цьому випадку будемо обчислювати фрактальну розмірність на основі збіжності значень клітинного та крапкового методів (Zhuravel \& Vorobel, 2007; Pat. 51439A Ukrainy, 2002). Результати обчислень подано на рис. 2.

Зображення $a$-г на рис. 2 представлені в діапазоні 256 градацій, а їх формування проводилося з розміром локальної апертури $3 \times 3,7 \times 7,15 \times 15$ та $31 \times 31$ пікселів відповідно. Доволі часто для представлення результатів побудови поля фрактальних розмірностей використовують не всі градації з діапазону від 0 до 256, а використовують квантування 3 меншою кількістю рівнів (див. рис. 2, д-ж), які обчислюють за виразом

$$
L^{*}(i, j)=f i x\left(\frac{L(i, j)}{256} \cdot q\right) \cdot \frac{256}{q},
$$

де: $f i x(\bullet)$ - операція заокруглення значень інтенсивностей вхідного зображення $L$ в меншу сторону; $q$ - кількість градацій на результатному зображенні $L^{*}$.

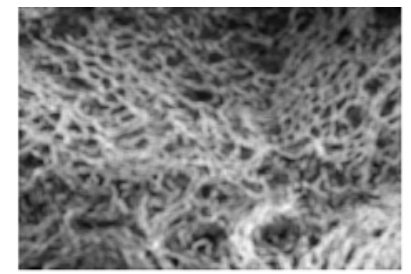

в) $15 \times 15, q=256$

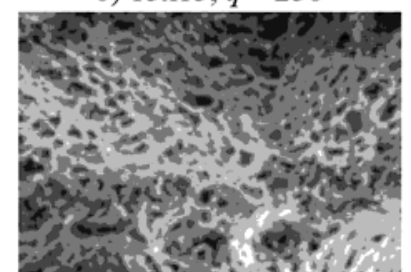

e) $15 \times 15, q=8$

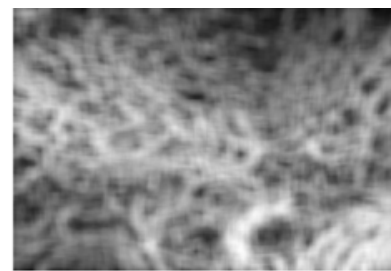

2) $31 \times 31, q=256$

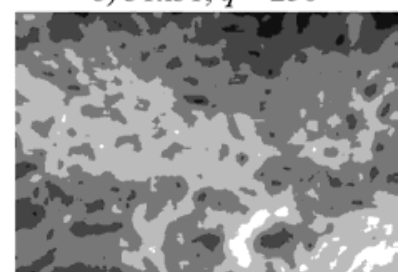

ж) $31 \times 31, q=4$

Рис. 2. Зображення полів фрактальних розмірностей для різних значень локальної апертури $n \times n$, кроку зміщення $k=1$ та відповідного діапазону інтенсивностей $q$ (д-ж)

Представлення результатного зображення 3 використанням виразу (1) є візуально зручнішим та дає змогу дещо збільшено побачити неоднорідності на досліджуваних зображеннях.

За результатами проведених досліджень встановлено, що розмір локальної апертури під час обчислення поля фрактальних розмірностей впливає на деталізацію неоднорідностей на результатному зображенні: менша апертура - більша деталізація і навпаки. Загалом розмір досліджуваних неоднорідностей повинен бути співмірним з розміром локальної апертури.

Вплив кроку зміщення локальної апертури $k$ на формування зображення поля фрактальних розмірностей. Дослідимо вплив кроку зміщення локальної апертури $k$ на формування зображення поля фрактальних розмірностей. Для цього на основі вхідного зображення (див. рис. 3) сформуємо поле фрактальних розмірностей за розміру локальної апертури $3 \times 3$ і кроку зміщення $k$, що дорівнюе 1,3 та 7.

Проведені дослідження показали, що збільшення кроку $k$ зміщення локальної апертури призводить до зменшення розміру результатного зображення поля фрактальних розмірностей та зменшення часу його обчислення. Значення $k>1$ доцільно використовувати під

час опрацювання зображень великого розміру за умови відсутності на них об'єктів з високою деталізацією.

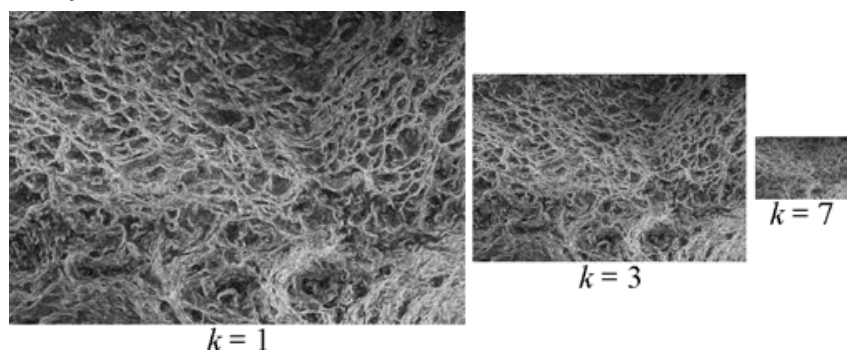

Рис. 3. Зображення поля фрактальних розмірностей за різних значень кроку зміщення $k$

Обчислення фрактальної розмірності зображень 3 різним діапазоном інтенсивностей та з використанням різних методів бінаризації. В описаних вище дослідженнях за вхідні використовувалися зображення 3 діапазоном інтенсивностей від 0 до 255. У багатьох випадках за вхідні можуть використовуватися зображення однієї і тієї ж сцени, отримані за різних умов освітлення, де значення інтенсивностей займають не весь діапазон, а тільки його частину. Дослідимо вплив діапазону інтенсивностей вхідного зображення на результати обчислення фрактальної розмірності. 
Для цього змоделюємо набір зображень з різними діапазонами інтенсивностей, використовуючи такий виpa3:

$$
L^{*}(i, j)=R \cdot\left(\frac{L(i, j)-L_{\min }}{L_{\max }-L_{\min }}\right),
$$

де $L(i, j)$ та $L^{*}(i, j)$ - елементи відповідно вхідного та перетвореного зображень з координатами $(i, j) ; R$ - діапазон інтенсивностей результатного зображення; $L_{\min }$, $L_{\max }$ - мінімальне та максимальне значення інтенсивностей вихідного зображення.

Для сформованих згідно з виразом (2) зображень обчислимо значення фрактальних розмірностей на основі найкращої збіжності клітинного та крапкового методів (Zhuravel \& Vorobel, 2007; Pat. 51439A Ukrainy, 2002; Volchuk, 2003). Оскільки згадані вище методи обчис-

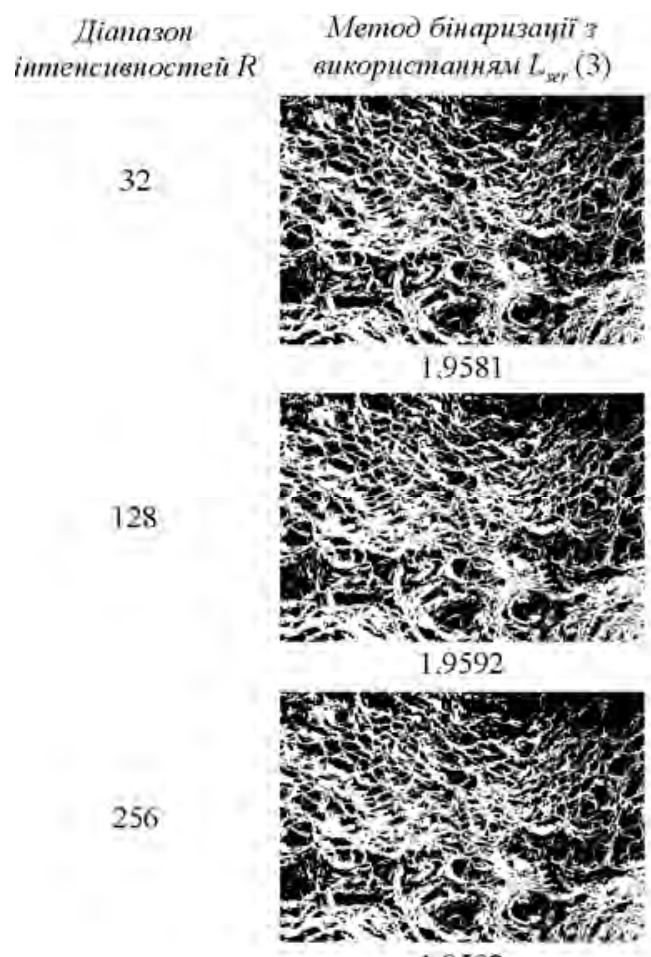

1,9592 лення фрактальної розмірності працюють тільки з бінарними зображеннями, то до сформованих на рис. 4 зображень необхідно застосувати один із методів бінаризації. Дослідимо вплив вибору цього чи іншого методу бінаризації (Zhuravel, 2012) на результати обчислень фрактальної розмірності. Для цього застосуємо три підходи до бінаризації зображень на рис. 4.

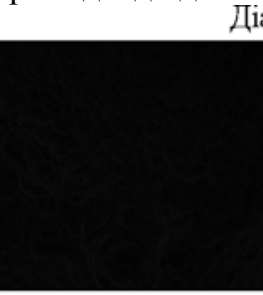

32 Дапазон інтенсивностей, $R$

Рис. 4. Зображення однієї сцени з різним діапазоном інтенсивностей

Метод бонаризачіï 3 бикористанням R/2 (4)

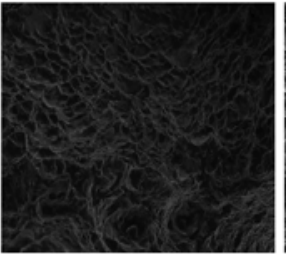

128

Мепод бінаризацї з оптикальвнем порогам *

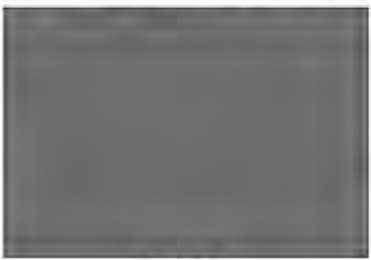

1,0194

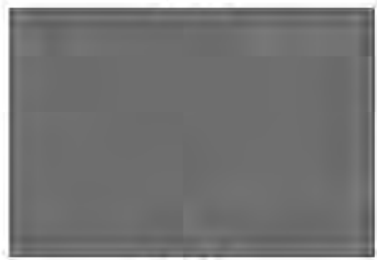

1,0194

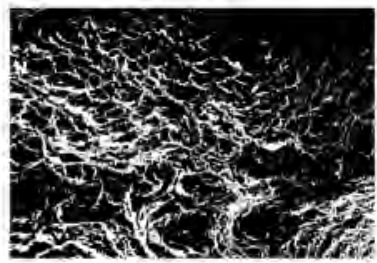

1,9193

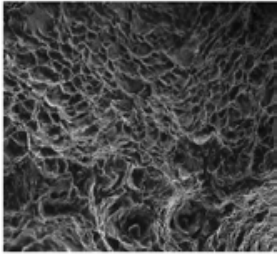

256

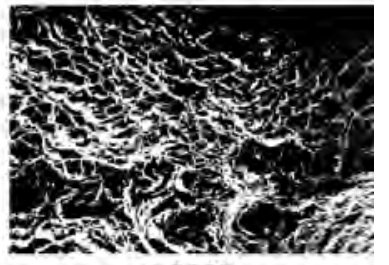
1,9380

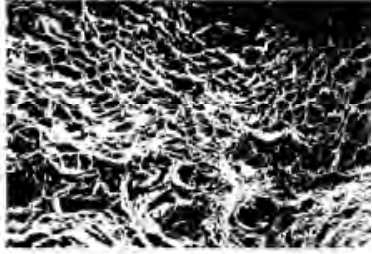
1,9524

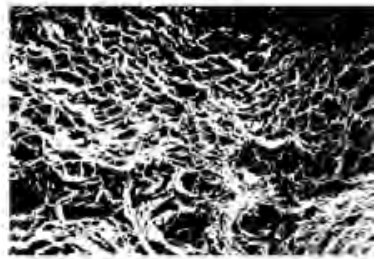

1,9524

Рис. 5. Результат бінаризації серії зображень на рис. 4 з використанням порогових значень $L_{s e r}, R / 2$ та оптимального порогу і відповідні їм фрактальні розмірності (* - Zhuravel, 2012)

Перший підхід до бінаризації буде реалізовано згідно з виразом

$$
L(i, j)=\left\{\begin{array}{c}
255, \text { при } L(i, j) \geq T ; \\
0, \text { при } L(i, j)<T,
\end{array}\right.
$$

де $T=L_{\text {ser }}=\frac{1}{N \cdot M} \sum_{i=1}^{N} \sum_{j=1}^{M} L(i, j)-$ усереднене значення інтенсивностей зображення $L$ з розмірами $N \times M$.

Другий підхід до бінаризації є подібним, але замість параметра $L_{s e r}$ за порогове значення $T$ буде використано значення середини діапазону інтенсивностей $R / 2$, яке за $R=256$ буде дорівнювати 128 , тобто $T=128$.

За третій підхід використаємо метод бінаризації зображень $з$ оптимальним порогом (Zhuravel, 2012), де поріг інтенсивнотей визначається за максимальною схожістю напівтонового та бінарного зображень. Результати опрацювання серії вхідних зображень (див. рис. 4) з використанням описаних вище підходів до бінарної сегментації подано на рис. 5.

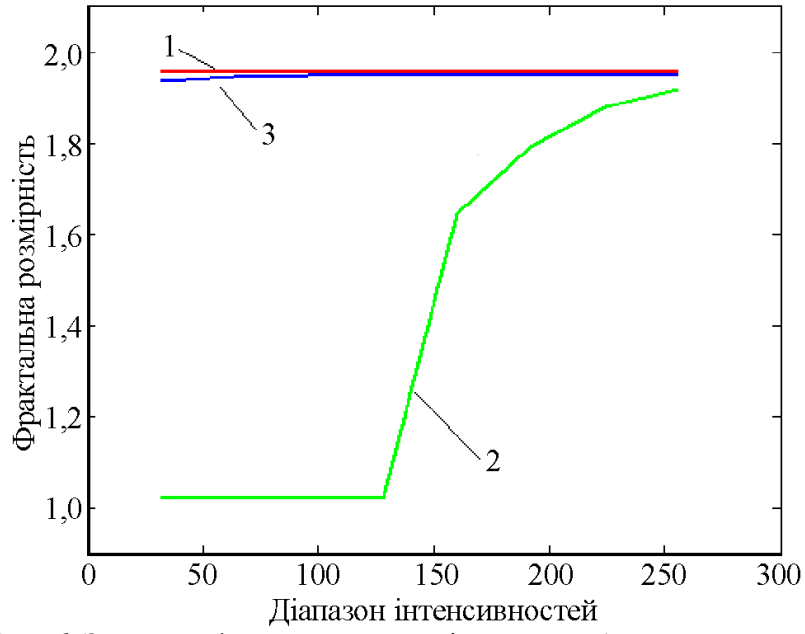

Рис. 6. Значення фрактальних розмірностей, обчислених для однісї серії зображень із застосуванням різних підходів до їх бінаризації: 1) з використанням порогового значення $\left.L_{s e r}, 2\right)$ з використанням за порогове значення $R / 2,3$ - 3 використанням оптимального порогу (Zhuravel, 2012) 
Для зручності порівняння та аналізу результатів обчислення фрактальних розмірностей (див. рис. 5), отриманих із застосуванням різних методів бінаризації, представимо їх на одному графіку (рис. 6). Отже, на рис. 6 представлено результати обчислення фрактальних розмірностей для серії зображень (див. рис. 4) однієї і цієї ж сцени, але з використанням різного діапазону інтенсивностей, що моделює формування зображень за різних умов зовнішнього освітлення.

Обчислення фрактальних розмірностей проводилися із застосуванням клітинного та крапкового методів (Pat. 51439A Ukrainy, 2002; Volchuk, 2003), які використовують за вхідні тільки бінарні зображення. Бінарні зображення формувалися на основі даної серії (див. рис. 4) трьома різними методами - 3 використанням за порогове значення $L_{s e r}$ (див. рис. 5 , другий стовпець), $R / 2$ (див. рис. 5 , третій стовпець) та 3 використанням оптимального порогу (див. рис. 5 , четвертий стовпець). Бінарні зображення, сформовані 3 використанням як порогового значення $L_{s e r}$ та 3 використанням оптимального порогу, забезпечують добру деталізацію, а зображення є майже схожими. Як результат, їх фрактальні розмірності є близькими за значеннями (див. рис. 6, криві 1 та 3) та не залежать від діапазону інтенсивностей вхідних зображень (див. рис. 4), а отже, і від умов зовнішнього освітлення під час формування цих зображень. Під час формування бінарних зображень 3 використанням порогового значення $R / 2$, важливе значення має діапазон інтенсивностей вхідних зображень. Якщо діапазон інтенсивностей вхідних зображень від
0 до $R / 2$, то бінарне зображення отримується абсолютно чорним. В інших випадках цей підхід теж не працює коректно, деякі деталі будуть на бінарному зображенні відсутніми, що призводить до занижених значень фрактальних розмірностей (див. рис. 6, крива 2). Підхід 3 використанням порогового значення $R / 2$ може бути застосовано тільки після нормалізації вхідних зображень (див. рис. 4) за рівнем інтенсивності. Отримані у роботі результати доцільно застосовувати під час опрацювання зображень 3 використанням фрактальних розмірностей для формування коректних результатів аналізу.

\section{Перелік використаних джерел}

Pat. 51439A Ukrainy. (2002). G06K9/00. Sposib vyznachennia fraktalnoi rozmirnosti zobrazhen / V. I. Bolshakov, Yu. I. Dubrov, F. V. Kryulin, V. M. Volchuk. Zareiestr. 02.02.02. [in Ukrainian].

Volchuk, V. M. (2003). Rozroblennia i doslidzhennia metodu vyznachennia yakisnykh kharakterystyk metalu na osnovi analizu fraktalnoi rozmirnosti yoho mikrostruktury. Candidate Dissertation for Technical Sciences (05.02.01 - Materials Science). Dnipropetrovsk. 186 p. [in Ukrainian].

Zhuravel', I. M., \& Svirs'ka, L. M. (2015). Measurement of the mean grain size in a metal by using fractal dimensions. Materials Science, 46(3), 418-420.

Zhuravel, I. M. (2012). Metod binaryzatsii metalohrafichnykh zobrazhen z optymalnym porohom. Shtuchnyi intelekt, 4, 142-147. [in Ukrainian].

Zhuravel, I. M., \& Vorobel, R. A. (2007). Obchyslennia fraktalnykh rozmirnostei z vykorystanniam poverkhnevoho intehralu. Vidbir $i$ obroblennia informatsii, 26(102), 95-98. [in Ukrainian].

Национальный университет "Львовская политехника", г. Львов, Украина

\section{ВЫБОР ПАРАМЕТРОВ ПРИ ВЫЧИСЛЕНИИ ПОЛЯ ФРАКТАЛЬНЫХ РАЗМЕРНОСТЕЙ ИЗОБРАЖЕНИЯ}

Результаты исследований в биологии, медицине, дистанционном зондировании Земли, материаловедении довольно часто представляются в виде цифровых изображений. Такие изображения, в основном, характеризуются не очень высоким визуальным качеством и сложной структурой. Все эти факторы существенно влияют на дальнейший анализ визуальных данных. Несмотря на интеллектуальные свойства зрительного восприятия, человек не может справиться с большим потоком информации и обеспечить необходимую производительность ее обработки, поэтому количественный анализ визуальных данных целесообразно перевести на вычислительные системы. Это привело к тому, что в последнее время развитие значительного сегмента современных информационных технологий нацелено на создание методов обработки и анализа визуальной информации. Результат процесса обработки и анализа является чрезвычайно важным, поскольку он лежит в основе принятия ответственных решений, например, в медицине или на производстве. Традиционные подходы, основанные на евклидовой геометрии, не всегда эффективны при обработке изображений со сложной структурой. Перспективным инструментарием при анализе таких изображений является фрактальная размерность. В общем случае, она позволяет вычислять только глобальные характеристики изображения. Для количественного анализа сложноструктурированных изображений целесообразно формировать поле фрактальных размерностей. Установлено, что при вычислении поля фрактальных размерностей важен правильный выбор настроек. Среди них следует выделить - размер локальной апертуры, шаг смещения и метод бинаризации. Размер локальной апертуры существенно влияет на детализацию при анализе изображения. Для лучшей локализации размер скользящей окрестности должен быть соразмерным с размером объектов интереса на изображении. Вторым важным параметром является шаг смещения локальной апертуры. Он пропорционален времени обработки и обратно пропорционален размеру изображения поля фрактальных размерностей. Увеличение шага смещения целесообразно при обработке изображений больших размеров, но это приводит к уменьшению детализации объектов. Поскольку большинство методов вычисления фрактальных размерностей использует за исходные бинарные изображения, важным является выбор метода пороговой бинаризации, который должен обеспечить наилучшую детализацию объектов интереса.

Ключевые слова: анализ цифровых визуальных данных; методы пороговой бинаризации; локальная апертура; шаг смещения; детализация объектов.

I. M. Zhuravel

Lviv Polytechnic National University, Lviv, Ukraine

\section{THE CHOICE OF PARAMETERS WHEN CALCULATING THE FRACTAL DIMENSION OF THE IMAGE}

The results of research in biology, medicine, remote sensing of the Earth, and material science are often presented in the form of digital images. Such images are mostly characterized by quite low visual quality and complex structure. All these factors significantly affect the further analysis of visual data. Despite the intellectual properties of visual perception, a person cannot cope with a 
large flow of information and provide the necessary productivity of its processing, so quantitative analysis of visual data is expedient to translate into computing systems. This led to the recent development of a significant segment of modern information technology aimed at creating methods for processing and analysing visual information. The result of processing and analysis is extremely important, since it is the basis of making responsible decisions, for example, in medicine or in the workplace. Traditional approaches based on Euclidean geometry are not always effective in the processing of images with complex structure. A promising tool for analysing such images is the fractal dimension. In the general case, it allows computing only the global characteristics of the image. For quantitative analysis of complex structured images it is expedient to form a field of fractal dimensions. The authors have revealed that when calculating the field of fractal dimensions it is important to choose the correct setting. We should highlight among them the following: the size of the local aperture, the bias step and the method of binarization. The size of the local aperture significantly affects detail when analysing the image. For best localization, the size of the slider should be commensurate with the size of the objects of interest in the image. The second important parameter is the step of displacement of the local aperture. It is proportional to the time of processing and is inversely proportional to the size of the image of the field of fractal dimensions. Increasing the shift step is advisable when processing large-sized images, but this reduces the detail of objects. Since most methods for calculating fractal dimensions use input binary images, it is important to choose the method of threshold binarization, which should provide the best detail of interest objects.

Keywords: analysis of digital visual data; methods of threshold binarization; local aperture; bias step; detailing of objects. 